\title{
Combination products
}

\author{
B. W. Cromie \\ M.B., F.R.C.P. \\ Hoechst Pharmaceuticals
}

\begin{abstract}
Summary
Drugs that do not have a critical dosage and are commonly used together, can justifiably be combined in a single product. Such combinations are more convenient to doctor and patient and have reduced risk of treatment error and drug interaction.

Combination products include more than one active drug, each of which has its own chemical and physical properties, so that they are complex formulations. Copies of combination products are, therefore, even less likely to have comparable performance than copies of single drugs.

Generic copies are encouraged by pharmacopoeial monographs and the current inclusion of complex formulations and combinations in the BP may allow a new era of clinical non-equivalence from products considered to be generically equivalent.
\end{abstract}

\section{Usage of combination products}

I have been asked to speak on the subject of combination products and it is correct that this topic be included in any symposium relating to prescribing, as something like $21 \%$ of all prescriptions in the National Health Service are for combination products.

In the past, there have been criticisms of combinations and suggestions that it would be preferable to prescribe single drug entities (MacGregor, 1966; Wade and McDevitt, 1966) but their usage has shown no decrease over the last 7 or 8 years (Cromie, 1969) and the overall trend is towards a steady increase.

\section{Rationale for combination products}

The reasons for this increasing trend are not difficult to find.

In the first place, it is well recognized that many patients require more than one drug at the same time to obtain the desired therapeutic effect. The principles behind multiple medication are legion but the main categories, with typical examples, are given in Table 1.

In the second place, it can be shown clearly that a great many commonly used drugs are administered at standard fixed dosage to between $50 \%$ and $70 \%$ of adult patients (Lea-Mendota Research Group, 1971; Intercontinental Marketing Statistics, 1971; Dollery, 1968). The majority of drugs given in this way do not have a critical dosage or a steep doseresponse curve.

Accepting these two situations, there are considerable and important practical advantages in giving the required drugs in a single formulation as a combination product.

TABLE 1

\begin{tabular}{|c|c|c|}
\hline Rationale & Drug combination & Disease \\
\hline $\begin{array}{l}\text { Potentiation of } \\
\text { effect }\end{array}$ & $\begin{array}{l}\text { Trimethoprim and } \\
\text { sulphonamide } \\
\text { Diuretic and hypotensive } \\
\text { agent }\end{array}$ & $\begin{array}{l}\text { Urinary infection, } \\
\text { bronchitis } \\
\text { Hypertension }\end{array}$ \\
\hline Reduced side-effects & Nystatin and tetracyclines & $\begin{array}{l}\text { Candida-prone } \\
\text { patients }\end{array}$ \\
\hline $\begin{array}{l}\text { Prevention of drug } \\
\text { resistance }\end{array}$ & P.A.S. +I.N.A.H. & $\begin{array}{l}\text { Prolonged anti-T.B. } \\
\text { therapy }\end{array}$ \\
\hline Extended coverage & $\begin{array}{l}\text { Antibacterial and antifungal } \\
\text { agents }\end{array}$ & $\begin{array}{l}\text { Mixed skin } \\
\text { infections }\end{array}$ \\
\hline $\begin{array}{l}\text { Multiple effects for } \\
\text { single entity }\end{array}$ & Oestrogen and progestogen & Oral contraception \\
\hline Co-existing diagnoses & Folic acid, iron & $\begin{array}{l}\text { Mixed anaemias of } \\
\text { pregnancy }\end{array}$ \\
\hline
\end{tabular}




\section{Advantages of combination products}

In the short time at my disposal today, I cannot cover all the arguments for and against combinations, which have been described before (Cromie, 1969, 1972), but would like to summarize three major features.

\section{(1) Reduces risk of errors in treatment}

Doctors use their skill and experience to decide on the optimum treatment for a patient. These efforts are completely wasted if the patient does not take the prescribed drugs as recommended and it has been shown repeatedly and consistently that this failure rate increases with the number of medicaments that have to be taken. Youth (Elwood, Waters and Greene, 1970) and age (Harman, 1971) may also be minor factors but the percentage of errors in taking prescribed medicines is directly proportional to the complexity of the regimen.

The greater the number of items, the greater the risk of medicines not being taken as prescribed. This has been shown in hospital (Vere, 1965), in outpatients (Clinite and Kabat, 1969; Latiolais and Berry, 1969) and in general practice (Malahy, 1966; Porter, 1969).

As Gatley states of general practice (Gatley, 1968) 'of the illnesses treated at home, the need is for increased simplicity of administration rather than for newer and better drugs'.

As many patients in practice need many drugs at standard dosages, only combinations can give the simplicity needed to cut down errors in treatment.

\section{(2) Reduces risk of drug interaction}

Whenever a patient is given more than one drug at the same time, there is a possible risk of drug interaction. The mechanisms of interaction are many and varied (Eichler, 1970; Ariens, 1969; Gross, 1969; Prescott, 1969; Solomon, Barakat and Ashley, 1971) and it has been rightly pointed out that it is no longer possible for practising clinicians to be aware of all possible risks (Ariens, 1969; Gross, 1969; MacGregor, 1969). Therefore, as stated by Dollery (1968) 'every time a physician adds to the number of drugs a patient is taking, he may devise a novel combination that has a special risk'.

If additional drugs are needed for the optimum management of the patient, this risk can be avoided by using a combination product, if one is available. With such a product, all the risks of interaction have been taken in experimental laboratories and controlled clinical trials instead of the unsupervised conditions of a patient in his home.

A further point, relevant to drug interaction, is that a combination product is three times as likely to be the only medication taken by a patient as single products (Cromie, 1969), so that the risk of inter- $\frac{3}{\infty}$ action with other drugs is correspondingly less.

\section{(3) Convenience to doctor and patient}

Convenience, often dismissed casually as 'mere convenience', is an important aspect of a practical business, such as the prescribing, describing, remembering and taking of medicines.

Doctors have strictly limited time with each patient (Reports from General Practice, 1965) and ${ }^{\infty}$ their failure in giving clear instructions is recognized $\vec{\circ}$ as a significant factor in causing errors with more complicated multi-tablet regimens (Drug and Thera- $\omega$ peutics Bulletin, 1965). The greater convenience and the ease of describing the taking of combination products will assist in reducing this source of error. if

From the point of view of the patient, the easier his medicines are to remember and take the better. Here again, the combination product approaches the ideal (Dollery, 1968) for the patient who needs more than one medicament.

A further advantage which usually applies is economy, as combination formulations are about 71 $20 \%$ cheaper on average than separate ingredients; $\stackrel{\mathbb{O}}{\mathrm{O}}$ quite apart from reduced dispensing, container and similar pharmacy costs.

\section{Disadvantages of combination products}

Apart from the doctrinal objections, which axe now regressing and have been covered elsewhere (Cromie, 1972), the main disadvantage of combination products would appear to be that some doctors use them without knowing what they contain or the rationale of their combined use. This has always been recognized as a possible hazard (Cromie, 1969, 1972) and a recent small survey in Canada (Byron, 1973) confirmed that, at least in Montreal, many doctors prescribe combination products without knowing enough about them.

Reviewing this survey, the Lancet (1973) suggests that better and sustained education is needed on drugs, their formulations and uses. This is certainly a role appreciated by the pharmaceutical industry and $I$ trust that communications between the industry and the profession are good enough to allow a better understanding of combinations in the $D$ United Kingdom than appears to obtain in Canada. Not that there is any cause for complacency and $N$ both the industry and other educators of the profession must be ever watchful.

Apart from this worrying problem of possible $\underset{\omega}{N}$ professional ignorance, there is no doubt that, if a doctor wants his patient to take more than one medicament actually as prescribed, then the best $\mathbb{D}$ chance is with a combination product, which is also? safer and more convenient.

There will, of course, always be some patients who 
require a different ratio of the active drugs but single entities are available for these. The majority should not be denied a major practical advantage because of a minority who cannot use them.

\section{Generic equivalent of drug combination}

Having summarized the arguments for and against combination products and having stressed that, in their correct place, they make a valuable contribution to practical therapeutics, we come to the main theme of today's symposium and consider the generic versus branded question, as it relates to combinations.

Much has already been said and I have no doubt that even more will be said about generic nonequivalence. It has been demonstrated that this can be a major factor, causing therapeutic confusion and potential danger, even with relatively simple tablets. It is easy to see that the problem is magnified many times over with formulations containing a number of active ingredients, as in a combination product.

Each active ingredient has its own solubility, stability, light sensitivity, physical and chemical incompatibilities and specific needs of particle-size, compression and release characteristics. It is obvious that the development and production of combination products, which has to take into account such considerations for a number of active drugs, is an extremely complex matter. Looking back at the formulations in which I have been involved over the years, the pharmaceutical development effort required to produce a satisfactory and dependable combination product averaged out at about forty times that needed for single drug products.

If there are doubts on the clinical equivalence of generic forms of single drugs, there must be grave concern with copies of branded combination products.

Fortunately, there are no generic copies of widely used modern speciality combinations, so that clinical non-equivalence is not yet a problem. The reason for this is that no modern combinations with expired patents are included in the British Pnarmacopoeia. There is no monograph, no generic name and all copies carry their own brand image and can be separately identified.

However, the situation could change rapidly. For years, we have had APC tablets and Mag. Hydroxide Mixture in the BP, allowing generic and branded forms of some older combinations, but these were products where clinical non-equivalence was not likely to be a major problem.

Now the BP has altered and includes highly complex formulations. It lists Slow Lithium Carbonate Tablets and Slow Orphenadrine Citrate Tablets. The many mechanisms of delayed release that are available make it clear that quite different absorption characteristics could be obtained from generic 'slowrelease' tablets, all conforming to BP specification.

The BP also includes the first modern combination product in Co-trimoxazole Tablets (better known as Bactrim and Septrin), a complex formulation of two antibacterial substances, still covered by patent protection but open to generic copies at a later date.

It must always be remembered that the generic name of a product only gives information on the chemical nature of the active ingredients. It says absolutely nothing about the pharmaceutical involvement and devices used to contain those active ingredients and ensure their consistent release pattern and subsequent bio-availability.

The naming and BP listing of such complex formulations and combination products, opens the door to a new and potentially more dangerous era of clinical non-equivalence from products that are considered to be generic equivalents.

\section{References}

ARIENS, E.J. (1969) Reduction of drug action by drug combination. Journal Mondial de Pharmacie, 12, 263.

BYRON, P. (1973) A hopefully biased pilot survey of a physician's knowledge of the content on drug combinations. Canadian Medical Association Journal, 109, 35.

Clinite, J.C. \& Kabat, H.E. (1969) Prescribed drugs . . . errors during self-administration. Journal of the American Pharmaceutical Association, 9, 450.

Cromie, B.W. (1969) Are drug combinations necessary? Journal Mondial de Pharmacie, 12, 287.

CRomie, B.W. (1972) Drug combinations. Current Medical Research and Opinion, 1, 78.

Dollery, C.T. (1968) Drug combinations. Prescribers Journal, 8, 7.

Drug and Therapeutics Bulletin (1965) Taking Medicines, 3, 30.

EICHLER, I. (1970) Incompatibilities of drugs. Osterreichische Arztezeitung, 25, 930,

ElWood, P.C., Waters, W.E. \& Greene, W.J.W. (1970) Evaluation of iron supplement in prevention of irondeficiency anaemia. Lancet, ii, 175.

GATLEY, M.S. (1968) To be taken as directed. Journal of the Royal College of Practitioners, 16, 39.

Gross, F. (1969) Enhancement of drug action by drug combinations. Journal Mondial de Pharmacie, 12, 229.

HaRman, J.B., (1971) Prescribing for the elderly. Prescribers Journal, 11, 142.

Intercontinental Marketing Statistics (1971) Personal communication.

LANCET (1973) Doctors and drug combinations, ii, 248.

LATIOlais, C.J. \& BerRy, C.C. (1969) Misuse of prescription medications by out-patients. Drug Intelligence and Clinical Pharmacy, 3, 270.

Lea-Mendota Research Group (1971) Physicians' attitude towards combinations.

Presented to Subcommittee on Public Health and Environment of the House Committee on Interstate and Foreign Commerce, Washington, U.S.A.

MACGregor, A.G. (1966) Drugs: the problem of protection. Focus (Sept.), 9.

MACGregor, A.G. (1969) Are drug combinations necessary? Journal Mondial de Pharmacie, 12, 281.

MaLAHY, B. (1966) The effect of instruction and labelling on the number of medication errors made by patients at home. American Journal of Hospital Pharmacy, 23, 283. 
Porter, A.M.W. (1969) Drug defaulting in a General Practice. British Medical Journal, 1, 218.

PrescotT, L.F. (1969) Pharmacokinetic drug interactions. Lancet, ii, 1239.

Reports from General Practice (1965) Report on present state and future needs of general practice. Journal of the Royal College of General Practitioners, 10, Supplement to No. 1., 26.
Solomon, H.M., Barakat, M.J. \& Ashley, C.J. (1971) Mechanisms of drug interaction. Journal of the American Medical Association, 216, 1997.

VERE, D.W. (1965) Errors of complex prescribing. Lancet, i, 370.

WADE, O.L. \& MCDEvitT, G.D. (1966) Prescribing and the British National Formulary. British Medical Journal, 2, 635.

\section{Discussion}

Professor A. Wilson of Liverpool University asked what guarantee could be given to the ordinary prescriber about the consistency of tablets. Dr Cromie argued that frequent checking of batches was carried out by reputable manufacturers but
Professor Wilson was not convinced that there was any way for the prescriber to decide which manufacturers are reputable and which are not. Dr Cromie hoped that over the course of many years, the experienced prescriber would get to know. 